6-16-2021

\title{
Effects of Surface and Top Wind Shear on the Spatial Organization of Marine Stratocumulus-Topped Boundary Layers
}

\author{
Monica Zamora Zapata \\ University of California - San Diego, mzamoraz@eng.ucsd.edu \\ Thijs Heus \\ Cleveland State University, t.heus@csuohio.edu \\ Jan Kleissl \\ University of California - San Diego
}

Follow this and additional works at: https://engagedscholarship.csuohio.edu/sciphysics_facpub

Part of the Physics Commons

How does access to this work benefit you? Let us know!

\section{Repository Citation}

Zapata, Monica Zamora; Heus, Thijs; and Kleissl, Jan, "Effects of Surface and Top Wind Shear on the Spatial Organization of Marine Stratocumulus-Topped Boundary Layers" (2021). Physics Faculty Publications. 431.

https://engagedscholarship.csuohio.edu/sciphysics_facpub/431

This Article is brought to you for free and open access by the Physics Department at EngagedScholarship@CSU. It has been accepted for inclusion in Physics Faculty Publications by an authorized administrator of EngagedScholarship@CSU. For more information, please contact library.es@csuohio.edu. 


\section{JGR Atmospheres}

\author{
RESEARCH ARTICLE \\ 10.1029/2020JD034162 \\ Key Points: \\ - The spatial organization of \\ Stratocumulus-topped boundary \\ layers is sensitive to variations of \\ surface and top wind shear \\ - Strong surface and top wind shear \\ combined reduce cloud fraction, \\ align updrafts and clouds with the \\ mean wind, and modify cloud top \\ - Updrafts and downdrafts are \\ identified: the tallest objects \\ dominate their composition and \\ contribution to turbulent fluxes
}

Supporting Information:

Supporting Information may be found in the online version of this article.

Correspondence to:

M. Zamora Zapata,

mzamoraz@eng.ucsd.edu

Citation:

Zamora Zapata, M., Heus, T., \& Kleissl, J. (2021). Effects of surface and top wind shear on the spatial organization of marine Stratocumulustopped boundary layers. Journal of Geophysical Research: Atmospheres, 126, e2020JD034162. https://doi. org/10.1029/2020JD034162

Received 30 OCT 2020 Accepted 28 APR 2021
(C) 2021. American Geophysical Union. All Rights Reserved.

\section{Effects of Surface and Top Wind Shear on the Spatial Organization of Marine Stratocumulus-Topped Boundary Layers}

\author{
Mónica Zamora Zapata $^{1}$ (), Thijs Heus ${ }^{2}$ (D) and Jan Kleissl ${ }^{1}$ (i) \\ ${ }^{1}$ Department of Mechanical and Aerospace Engineering, University of California, San Diego, La Jolla, CA, USA, \\ ${ }^{2}$ Department of Physics, Cleveland State University, Cleveland, OH, USA
}

\begin{abstract}
The convective nature of Stratocumulus topped boundary layers (STBL) involves the motion of updrafts and downdrafts, driven by surface fluxes and radiative cooling, respectively. The balance between shear and buoyant forcings at the surface can determine the organization of updrafts between cellular and roll structures. We investigate the effect of varying shear at the surface and top of the STBL using Large Eddy Simulations, taking DYCOMS II RF01 as a base case. We focus on spatial identification of the following features: coherent updrafts and downdrafts, and observe how they are affected by varying shear. Stronger surface shear organizes the updrafts in rolls, causes less well-mixed thermodynamic profiles, and decreases cloud fraction and liquid water path (LWP). Stronger top shear also decreases cloud fraction and LWP more than surface shear, by thinning the cloud from the top. Features with stronger top than surface shear are associated with a net downward momentum transport and show early signs of decoupling. Classifying updrafts and downdrafts based on their vertical span and horizontal size confirms the dominance of tall objects spanning the whole STBL. Tall objects occupy $30 \%$ of the volume in the STBL, while short ones occupy less than $1 \%$. For updraft and downdraft fluxes, these tall objects explain $65 \%$ of the vertical velocity variance and $83 \%$ of the buoyancy flux, on average. Stronger top shear also weakens the contribution of downdrafts to the turbulent fluxes and tilts the otherwise vertical development of updrafts.
\end{abstract}

Plain Language Summary Stratocumulus clouds form in the atmospheric boundary layer, close to the Earth's surface. Turbulence in this boundary layer causes large circulation composed of strong motions going up and down called updrafts and downdrafts. At the surface and top of the boundary layer, wind speed can change abruptly, generating wind shear. We investigate the effect of changes in wind shear on the organization of the clouds, updrafts, and downdrafts. By simulating atmospheric flow, we observe that stronger surface wind reduces the amount of clouds, strong top shear modifies the shape of cloud tops, and only when shear is strong both at the surface and top, clouds are elongated in the wind direction. Of all the updrafts and downdrafts found, the tallest ones dominate in volume occupied and in the transport of momentum, heat, and moisture in the boundary layer.

\section{Introduction}

Stratocumulus (Sc) clouds cover 23 percent of the Earth's ocean surface (Wood, 2012) and are important for the global climate because of their high albedo (Zelinka et al., 2017), as well as for solar power generation due to their presence over coastal land (Clemesha et al., 2017). Both the albedo and solar variability are directly linked to the spatial organization of the cloud field. At large scales (tens of kilometers), mesoscale shallow convection organizes in rolls, open cells, and closed cells with different cloud fractions (Atkinson \& Wu Zhang, 1996), while at smaller scales (a kilometer), boundary layer processes also impact the organization of Sc by affecting the development of updrafts and downdrafts.

The Stratocumulus Topped Boundary Layer (STBL) forcings act at both the surface and the BL top and determine the temporal and spatial evolution of the cloud layer. The balance between surface buoyancy flux and surface wind shear affects the turbulence and organization within the STBL. In shear-dominated convective boundary layers (CBL), streaky structures develop near the surface, in buoyancy-dominated CBLs, coherent updrafts form near the surface and transport momentum throughout the CBL (Salesky et al., 2017); when both shear and buoyancy are important, coherent updraft rolls develop in the lower half 
of a STBL (Moeng \& Sullivan, 1994) and, in the case of shallow cumulus clouds, lead to an increased cloud fraction (Park et al., 2017).

Near the top of the STBL, radiative cooling promotes a sharp temperature inversion, and there is entrainment of air from the free troposphere, and wind shear across the interface. The top of the STBL represents a sheared stratified layer with updrafts and downdrafts underneath. Radiative cooling is believed to drive downdrafts in the STBL (Wood, 2012), although recent studies question that causal relationship (Matheou \& Teixeira, 2019). Wind shear across the inversion can dilute the cloud top by enhancing turbulent mixing (Kopec et al., 2016; McMichael et al., 2019; Mellado et al., 2014; Wang et al., 2008, 2012), caused by the development of Kelvin-Helmholtz waves (Kim et al., 2003; Wang et al., 2012).

The main coherent structures in STBLs are updrafts and downdrafts, and their organization is tightly linked to the turbulence and spatial features of the cloud field. The strong mixing by updrafts and downdrafts promotes the well-mixed profiles that are characteristic of STBLs (Lilly, 1968). Their importance in non-local mixing has led to the development of mass flux parameterizations with consideration of downdrafts to improve turbulent parameterizations in NWP models (Han \& Bretherton, 2019; Wu et al., 2020). Recent studies have focused more closely on the identification of updrafts and downdrafts in the STBL (Brient et al., 2019; Chinita et al., 2018; Davini et al., 2017), finding that these structures are responsible for nearly $80 \%$ of the heat and moisture fluxes in the STBL (Brient et al., 2019). Another recent study has found that the horizontal scales of STBL convection tend to grow in time, a phenomenon that is enhanced by spatial perturbations of radiative cooling, that is, more variability of cloudiness (Zhou \& Bretherton, 2019). A better understanding of the dynamics and sensitivity of these structures to physical processes could further improve turbulence parameterizations tailored for STBLs.

In summary, surface and top conditions cause spatial differences in the organization of Sc clouds as well as of updrafts and downdrafts. The literature survey above reveals several open research questions: (1) for surface shear, it is unknown if the development of rolls increases Sc cloud fraction, as is the case for shallow cumulus clouds; (2) for top shear, it is unknown if the decreased cloud fraction has an impact on STBL spatial features and if gravity waves affect the cloud field; (3) while it is known that updrafts and downdrafts can change their structure from cells to rolls with increasing surface shear (Moeng \& Sullivan, 1994), we do not know how their contribution to the turbulent fluxes in the STBL is affected by the relative magnitudes of surface and top shear, and how their contribution depends on the size of the structures.

In this work, we study the effects of varying the surface and top wind shear on the spatial structure of STBLs, which touches on all three open questions mentioned above. Using LES, we analyze the differences in cloud fraction and cloud shape, the changes in the organization of coherent structures, and their contributions to the turbulent fluxes of the STBL. Section 2 describes the LES simulations, the method to identify the coherent structures, and the geometric classification of coherent structures based on size and location. Section 3 present the results and discussion, including the effect of wind shear on the thermodynamic profiles and turbulent fluxes (Section 3.2), the spatial organization of the cloud fields and structures (Section 3.3), and the contributions of the classes of coherent structures on the total turbulent fluxes in the STBL (Section 3.4). Section 4 contains the conclusions.

\section{Methods}

\subsection{Simulation Setup}

We vary the surface and top wind speed profiles to create combined variations of shear around a reference case. The first research flight of the DYCOMS II field campaign (RF01, Stevens et al. (2005)) is the reference case for our simulations, since it is a Sc case that has been extensively studied (e.g., Matheou \& Teixeira, 2019; Mellado et al., 2014; Pedersen et al., 2016; Schulz \& Mellado, 2018).

To control the influence of the surface wind shear, we consider five progressions of the initial wind profile in the STBL $\left(u_{0}, v_{0}\right)$ from the reference RF01 case (CTRL) to a case with zero mean wind speed (000U). For the RF01 case, the initial wind speed magnitude, $r_{0}=8.9 \mathrm{~m} \mathrm{~s}^{-1}$, is above the third quartile of the 28-year record of wind speeds for a buoy off the coast of Santa Monica, CA (NOAA, 2021), indicating that our control case is representative of large wind speeds in this area and the progression to smaller wind speeds is consistent 

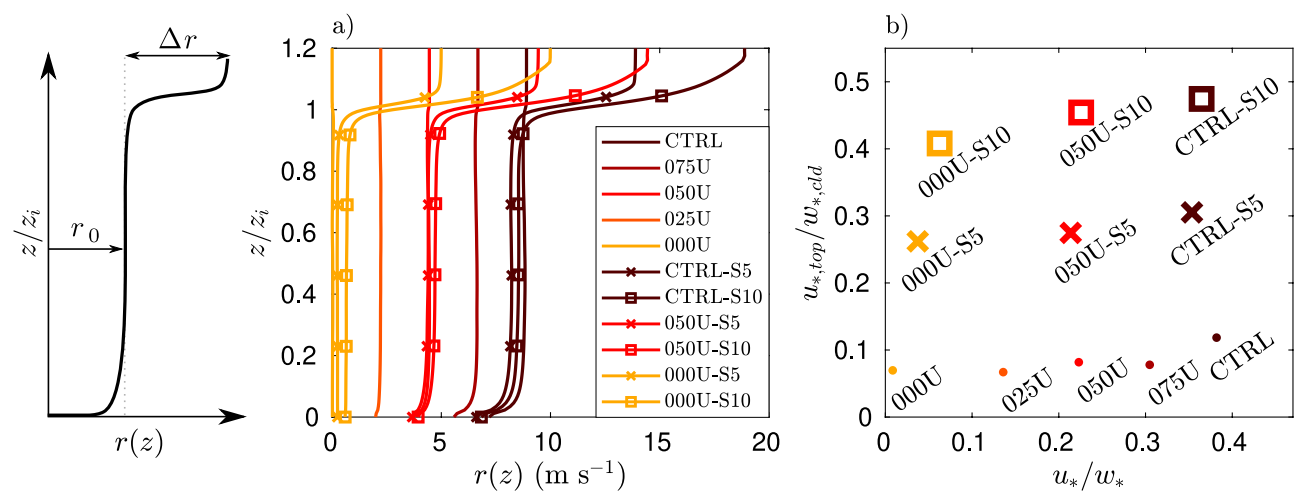

Figure 1. Wind speed variations for all the cases considered: (a) profiles of wind speed magnitude $r(z)$, and (b) case description in the parameter space defined by non-dimensional measures of surface shear $\left(u_{*} / w_{*}\right)$ and top shear $\left(u_{* \text {,top }} /\right.$ $w_{*, \text { cld }}$. Values presented are 15 min averages at hour 4 .

with the observations. All of these cases have no wind shear at the top of the STBL. To minimize the development of top shear during the simulation (as remarked by Fedorovich and Conzemius (2008), who argued that it can artificially enhance entrainment in LES), we nudge the wind velocity field in the whole domain with a timescale of $0.5 \mathrm{~h}$. Nudging, also known as Newtonian relaxation, adds a term to the horizontal flow component equations ( $u$ and $v$ ), with the goal of enforcing the mean wind speed to follow the reference values. The nudging terms are

$$
\left(\frac{\partial u}{\partial t}\right)_{\text {nudge }}=\frac{u_{0}-u}{\tau} \text { and }\left(\frac{\partial v}{\partial t}\right)_{\text {nudge }}=\frac{v_{0}-v}{\tau}
$$

where $u_{0}$ and $v_{0}$ are the reference initial wind speed components and $\tau$ is the nudging timescale. The wind speed magnitude $r(z)=\sqrt{u^{2}+v^{2}}$ in Figure 1a confirms that the top shear for these cases is minimal.

We also vary the wind shear at the top of the STBL in the following three base cases: the reference case (CTRL), with an initial wind speed profile as Stevens et al. (2005), and the cases with half of the CTRL wind speed (050U) and no wind speed (000U). We impose an initial top shear of $|\Delta r|=\{5,10\} \mathrm{m} \mathrm{s}^{-1}$ (denoted as cases $\mathrm{S} 5$ and S10, respectively), where $\Delta r=r_{\mathrm{FT}}-r_{0}$ is the jump between the tropospheric $\left(r_{\mathrm{FT}}\right)$ and initial STBL wind speed magnitudes $\left(r_{0}\right)$. No nudging is imposed on the top-wind sheared cases; the initial wind profile has the desired wind jump and is let to evolve in time. While the wind speed in the STBL decays in time, the tropospheric air is not turbulent and not strongly affected by STBL dynamics, meaning the wind speed above stays nearly constant. Therefore, the wind speed jumps magnitudes change slightly from the initial values but relative differences are maintained for no top shear, S5 and S10 cases. The initial values of $|\Delta r|=\{5,10\} \mathrm{m} \mathrm{s}^{-1}$ agree with the referential wind speed shear reviewed by Wang et al. (2012) from VOCALS-REx (from 5.6 to $9.2 \mathrm{~m} \mathrm{~s}^{-1}$ ) and are stronger than the observed jump during DYCOMS II of $3.8 \mathrm{~m} \mathrm{~s}^{-1}$ (Faloona et al., 2005). Refer to Table S1 in the supporting information for further details on the initial wind profile.

The flow is resolved using the UCLA-LES code in a large domain size of $14 \times 14 \mathrm{~km}$ to allow for the development of stronger updraft and downdraft motions (Pedersen et al., 2016). We use a horizontal resolution of $\Delta x=\Delta y=35 \mathrm{~m}$ and a vertical resolution of $\Delta z=10 \mathrm{~m}$ in the lower part of the STBL, reduced to a minimum $\Delta z=5 \mathrm{~m}$ near the STBL top, with a total of $400 \times 400 \times 131$ points. Surface fluxes are fixed throughout the simulation, with sensible and latent heat fluxes of SHF $=15 \mathrm{~W} \mathrm{~m}^{-2}$ and LHF $=115 \mathrm{~W} \mathrm{~m}^{-2}$, and we use the parameterized longwave radiation, following Stevens et al. (2005).

\subsection{A Parameter Space for Wind Shear Variations}

Previous studies have shown that the organization of the updrafts in the STBL depends on the balance between surface shear and buoyancy, and more precisely on the stability parameter $\eta=-z_{i} / L_{\mathrm{ob}}$ (Park \& 


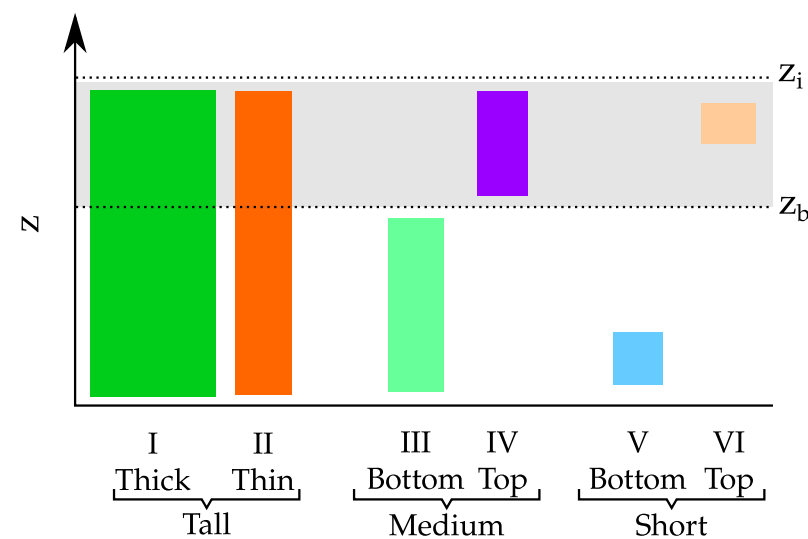

Figure 2. Visual representation of the proposed object classification. The gray area represents the cloud layer.
Baik, 2014; Salesky et al., 2017), where $z_{i}$ is the height of the STBL (defined here as the height of the maximum gradient of liquid water potential temperature, $\theta_{l}$ ), and $L_{\mathrm{ob}}$ is the Obhukov length,

$$
L_{\mathrm{ob}}=\frac{-z_{i}}{\kappa}\left(\frac{u_{*}}{w_{*}}\right)^{3},
$$

where $\kappa$ is the von Kármán constant, $u *$ is the friction velocity, and $w *$ is the convective velocity scale: $w_{*}^{3}=g z_{i} \overline{w^{\prime} \theta_{v 0}^{\prime}} / \theta_{v 0}$, where $\theta_{v 0}$ is a reference surface virtual potential temperature, and $\overline{w^{\prime} \theta_{v 0}^{\prime}}$ is the surface virtual potential temperature flux.

Since all cases have a similar STBL height, $z_{i}$, we can represent surface shear by measuring $u_{*} / w_{*}$ instead of $L_{o b}$. In a similar fashion, we can represent top shear with appropriate shear and buoyancy scales near the top of the STBL. We choose an in-cloud buoyancy reference convective velocity (Ghonima et al., 2016),

$$
w_{*, \mathrm{cld}}^{3}=\frac{g}{\theta_{v, 0}} \int_{z_{b}}^{z_{i}} \overline{w^{\prime} \theta_{v}^{\prime}} d z
$$

where $z_{b}$ is the cloud base height, and we compute a top friction velocity based on the momentum flux at the top of the STBL, $u_{* \text {,top }}=\left({\overline{u^{\prime} w^{\prime}}}_{\text {top }}^{2}+{\overline{v^{\prime} w^{\prime}}}_{\text {top }}^{2}\right)^{1 / 4}$. With this set of scaling parameters, the variations of surface and top shear can be presented in the parameter space defined by $u_{*} / w_{*}$ and $u_{*, \text { top }} / w_{*, \text { cld }}$, as shown in Figure 1b.

\subsection{Structure Identification and Classification}

Updrafts and downdrafts are loosely defined as coherent strong upward and downward motions, and previous works have used different approaches for their detection: thresholds of flow properties (Moeng \& Sullivan, 1994), tracers (Brient et al., 2019; Couvreux et al., 2010), both flow properties and tracers (Davini et al., 2017; Park et al., 2016), or joint probability density functions (Chinita et al., 2018). While thresholds of flow properties will result in identifying the strongest motions in the STBL, tracers identify the strongest effective transport in the vertical direction. Both methods are sensitive to parameters choices such as thresholds or tracer timescales. Couvreux et al. (2010) compared a tracer method to a threshold method, finding differences in the points that compose each identified structure, although these differences were more expressed in the surface and top regions. The coherent structures then intrinsically depend on the detection method and their parameters (timescales and thresholds). We opt for a threshold approach due to its simplicity.

We consider a set of coherent structures consisting of updrafts and downdrafts, defined by the vertical velocity anomalies $w^{\prime}(x, y, z)=w(x, y, z)-\bar{w}(z)$, where $\bar{w}(z)$ is the horizontal average of $w(x, y, z)$ at height $z$. To identify coherent structures, we first apply a spatial Gaussian filter. As per Text S1 in the supporting information, the number of objects stabilizes for larger filter radii; the chosen radius is 2 voxels. For the filtered variable $w$, the points that belong to a updrafts satisfy $w^{\prime}>\sigma_{w}(z)$, or $w^{\prime} \leq-\sigma_{w}(z)$ in the case of downdrafts, where $\sigma_{w}(z)$ is the standard deviation of $w$ at each vertical level (as per Text S2 in supporting information, a reduction of $10 \%$ in the threshold results in 5\% higher contributions of tall updrafts and downdrafts to the vertical velocity variance). An object is composed of the detected points that are contiguous in any direction (if either faces, edges, or corners are connected), similarly to Brient et al. (2019). We also account for the periodicity of the LES domain by joining objects that are adjacent at the lateral sides of the domain.

We classify the identified updraft and downdraft objects based on their geometrical properties as shown in Figure 2. For each object, we compute its lowest height $z_{0}$, height span in the STBL $\Delta z$, total volume $V$, and an equivalent horizontal length scale $L_{h}=\sqrt{V / \Delta z}$. For updrafts and downdrafts, we find structures that 
span the whole STBL height, $z_{i}$. We also find smaller structures occupying the subcloud or cloud regions. Therefore, we classify the structures as tall $\left(\Delta z>p_{95, \Delta z}\right)$, medium $\left(p_{75, \Delta z}<\Delta z \leq p_{95, \Delta z}\right)$, or small $\left(\Delta z \leq p_{75, \Delta z}\right)$, where $p_{75, \Delta z}$ is the 75th percentile of $\Delta z$. Note the use of relatively high percentiles to capture the positively skewed size distribution. Furthermore, tall structures are sub-classified by their horizontal size $L_{h}$ as either thick ( $L_{h}>\overline{L_{h}}$, category I) or thin structures $\left(L_{h} \leq \overline{L_{h}}\right.$, category II), where $\overline{L_{h}}$ is the average horizontal length of the tall objects. Medium and small objects are sub-classified by their position in the STBL: bottom objects occupy the subcloud region $\left(z_{0}<z_{b}\right.$, categories III and V, where $z_{b}$ is the horizontally averaged cloud base height and local cloud base is typically situated around $650 \mathrm{~m}$, with a spatial variability of about $50 \mathrm{~m}$ ) and top objects occupy the cloudy region $\left(z_{0} \geq z_{b}\right.$, categories IV and VI). In summary, we have six geometric categories for the identified objects that form updrafts and downdrafts, denoted as $\left\{\mathrm{UD}^{\mathrm{I}}, \ldots, U D^{V I}\right\}$ and $\left\{\mathrm{DD}^{I}\right.$, $\left.\ldots, D D^{V I}\right\}$.

\section{Results and Discussion}

We first describe the effects of the different shear configurations on the general properties of the STBL, and then analyze the spatial features and turbulent contributions of the updrafts and downdrafts using the proposed object identification method. We choose to keep the physical variables instead of non-dimensionalizing to preserve physical insights. Other studies such as Schulz and Mellado (2018) or Salesky et al. (2017) only examine shear at the top or the bottom and then the normalization approach is dictated based on the respective scales. But in our study, both top and surface conditions are varied.

\subsection{Time Evolution}

For most cases, the evolution of vertically integrated TKE, cloud fraction and liquid water path (LWP) reaches a stable state around hour 3, after the spin-up period (Figure 3). While for the cases with no top shear, cloud fraction is relatively stable after hour 2 (Figure $3 b$ ), the cases with top shear (bottom row) still show a significant evolution until hour 4 (Figure 3f). Therefore, we perform the rest of the analyses at either a snapshot at hour 4 (for the structure detection) or the 15 min ending at hour 4 (representing 1 eddy turnover time for turbulence statistics).

Shear has a strong effect on aggregated cloud properties. The surface shear cases all show a link between stronger surface shear and reduced cloud fraction, LWP, and cloud thickness (Figures 3b-3d and 3f-3h). The top sheared cases show a similar tendency where the presence of top shear reduces cloud fraction and LWP for the 050U-S5,S10 and CTRL-S5,S10 cases. For the 000U-S5,S10 cases, the results are inconsistent; LWP is similar and cloud fraction slightly increases for stronger top shear.

\subsection{Thermodynamic Profiles and Turbulent Fluxes}

We observe slight differences in the average thermodynamic profiles that help to explain the differences in LWP, cloud thickness, and cloud fraction. The profiles of total water mixing ratio $q_{t}(z)$ and liquid water potential temperature $\theta_{l}(z)$ seem similar for all cases but closer inspection reveals different slopes within the STBL and different transitions in the inversion region. The 000U case has the most uniform profiles (Figures 4a and 4c), the coldest STBL (lowest $\theta_{l}(z)$ ), and a sharp inversion (Figures $4 \mathrm{~b}$ and $4 \mathrm{~d}$ ). The more well-mixed cases are linked to a more adiabatic profile of liquid water mixing ratio $q_{l}(z)$ (Figure $4 \mathrm{e}$, with the gray dashed line showing an adiabatic profile), agreeing with the greatest LWP in Figure 3c.

All cases with only surface shear show a consistent sharp inversion region. Stronger surface sheared cases display a warmer STBL, which could be caused by the reduced cooling of a thinner cloud layer. The cases with top shear all display less well-mixed profiles than the surface-sheared cases. This is an interesting result, as it shows that the top shear indeed affects the rest of the STBL. The dilution of the inversion region (i.e., a less sharp inversion) for the top sheared cases has been extensively reported and linked to reduced cloud fraction due to increased mixing atop and entrainment of drier air into the STBL (McMichael et al., 2019; Kopec et al., 2016; Mellado et al., 2014; Wang et al., 2008, 2012). 

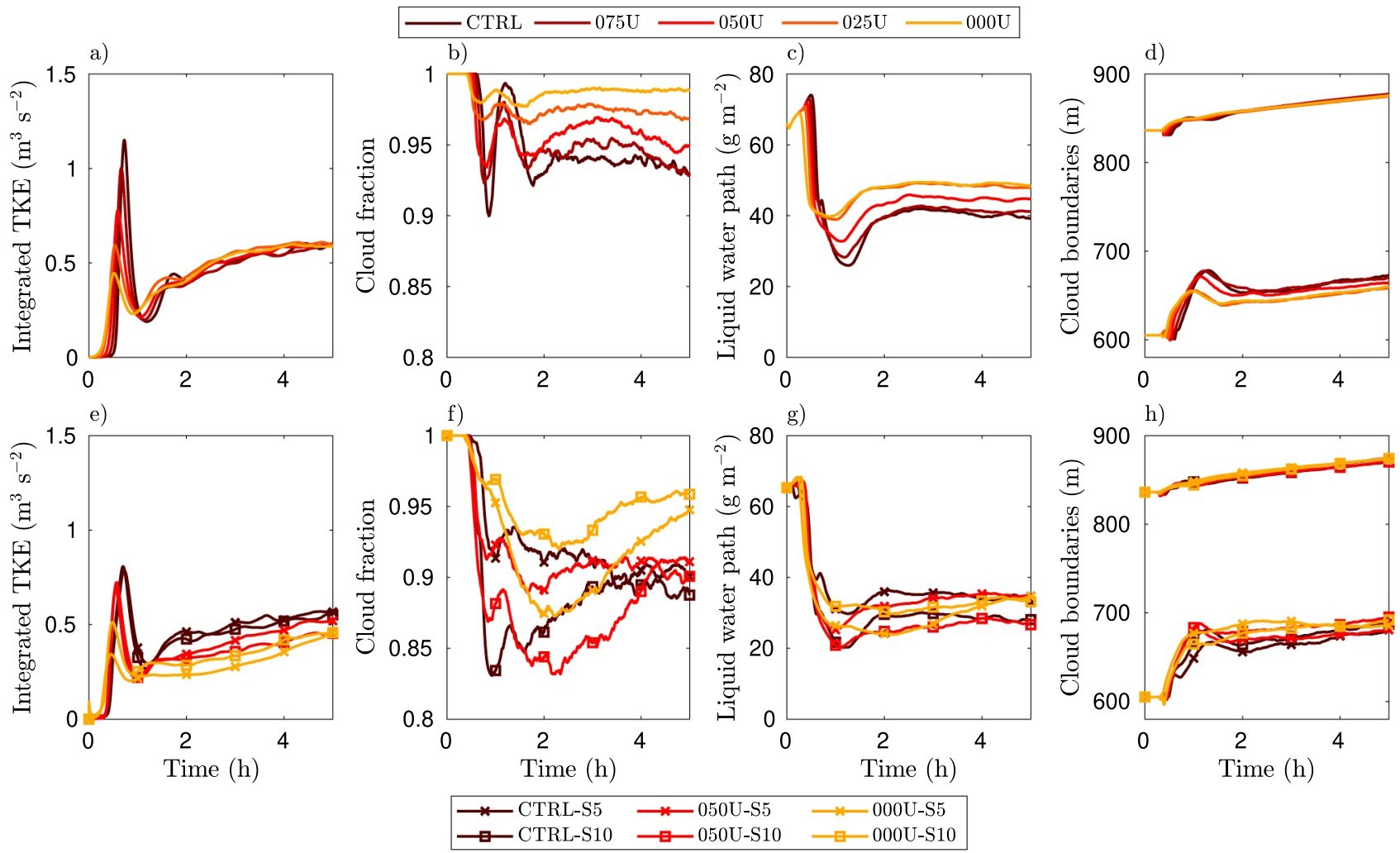

Figure 3. Time evolution of domain properties for all cases with a time resolution of $15 \mathrm{~s}$, including (a), (e) vertically integrated TKE, (b), (f) cloud fraction, (c), (g) LWP, and (d), (h) mean cloud base and top heights. The top row shows the cases without top shear, while the bottom row shows the cases with top shear. Flow dynamics are well maintained after hour 2. LWP, liquid water path.

The turbulent fluxes also show distinct features of surface and top shear. Stronger surface shear weakens $\overline{w^{\prime} w^{\prime}}$, consistent with the lower cloud content which can weaken the STBL circulation, but it does not weaken the sum of horizontal velocity variances $\sigma_{r}^{2}={\overline{u^{\prime} u^{\prime}}}^{2}+{\overline{v^{\prime} v^{\prime}}}^{2}$, resulting in a similar TKE profile (not shown). Stronger top shear reduces both $\overline{w^{\prime} w^{\prime}}$ and $\sigma_{r}^{2}$, and shows early signs of decoupling in the 000U-S5, 000U-S10, 050U-S5, and 050U-S10 cases, as evidenced by the reduced vertical velocity variance in the center of the STBL surrounded by two local maxima. The sum of horizontal momentum fluxes $F_{r}=\left(\overline{u^{\prime} w^{\prime}}+\overline{v^{\prime} w^{\prime}}\right)^{2 / 2}$ as computed by Lin et al. (1996) exhibits signatures of both surface and top shear, in that, considering the gradient of $F_{r}$, an increased downward momentum transport develops for the 000U-S5, 000U-S10, and 050US10 cases. The buoyancy and heat fluxes (not shown) are consistent with the differences in cloud thickness and LWP, with stronger surface and top shear developing weaker in-cloud and subcloud buoyancy fluxes.

Finally, while the enhanced turbulent mixing for increased top shear is evident in the thickening of the inversion region (Figures $4 \mathrm{~b}$ and $4 \mathrm{~d}$ ), we also compute the entrainment velocity as

$$
w_{e}=\frac{d z_{i}}{d t}+D z_{i}
$$

where the large scale divergence $D=3.75 \times 10^{-6} \mathrm{~s}^{-1}$ (Stevens et al., 2005). Table 1 shows that the average entrainment rate is nearly identical for the cases without top shear; by nudging the velocity in the whole domain we deliberately avoided the development of top shear which artificially enhances the entrainment, as explained by Fedorovich and Conzemius (2008). Top shear does not show a clear effect on $w_{e}$ : CTRL-S10 and 000U-S10 entrain stronger but CTRL-S5 and 050U-S5,S10 entrain weaker than the cases without top shear. Since the entrainment rate is sensitive to the definition of $z_{i}$ (Schulz \& Mellado, 2018) (here: where the gradient of $\theta_{l}$ is maximum), as well as to the cloud content in each case due to the cloud-radiation 

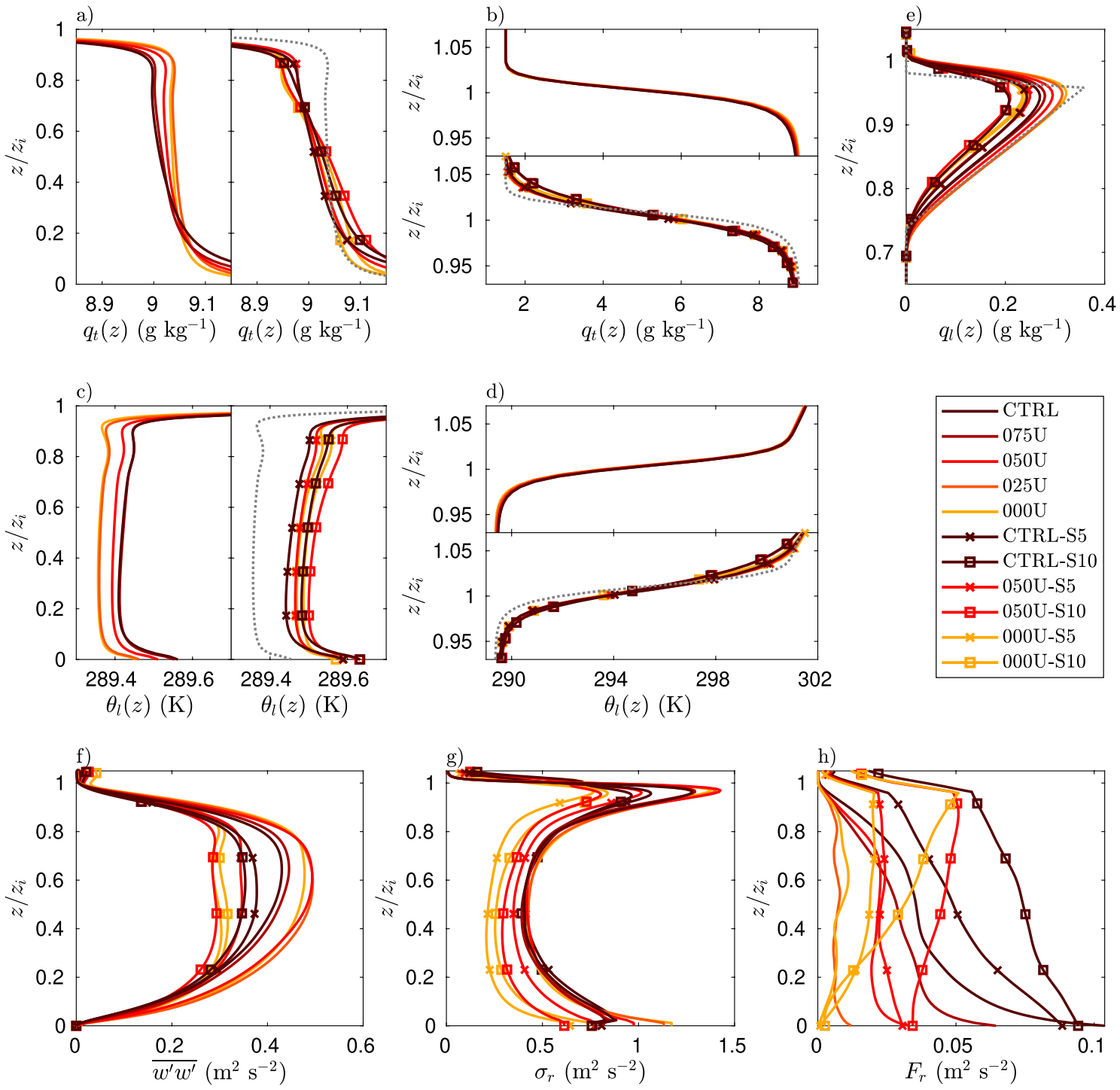

Figure 4. Vertical domain-averaged profiles of total water mixing ratio $q_{t}(z)$ with a closer look at (a) the boundary layer and (b) the inversion region; liquid water potential temperature $\theta_{l}(z)$ with a closer look at (c) the boundary layer and (d) the inversion region; and (e) liquid water mixing ratio $q_{l}(z)$, with different abscissa ranges for (a) and (b), and (c) and (d). Turbulence statistics of (f) vertical velocity variance $\overline{w^{\prime} w^{\prime}}$, (g) net horizontal velocity variance $\sigma_{r}^{2}$, and (h) net horizontal momentum flux $F_{r}$. All profiles are $15 \mathrm{~min}$ averages at hour 4 . The gray dashed lines in (a)-(d) display the 000U for ease of comparison to topsheared cases, and in (e) display the adiabatic $q_{l}$ profile for the $000 \mathrm{U}$ case.

feedback (Matheou \& Teixeira, 2019), and since we cannot isolate this feedback, we cannot confirm the expected increased entrainment velocity with stronger top shear (Schulz \& Mellado, 2018; Wang et al., 2012). Tracer methodologies could help answer this question.

According to Schulz and Mellado (2018), who used the same base case in a DNS study on top shear, a critical $\Delta r \simeq 4 w_{* \text {,cld }}$ marks the transition from convection-dominated to shear-dominated flow in the top stratification layer. This criterion places all of our S5 and S10 cases in the shear-dominated regime (Table 1), where wind shear can amplify the buoyancy reversal and destabilize the cloud layer (Mellado et al., 2014). Implications of the dominant physics regime for the spatial arrangement of coherent structures are not obvious. Schulz and Mellado (2018) also derived that a velocity jump of $10 \mathrm{~m} \mathrm{~s}^{-1}$ would achieve "critical depletion," that is, a level of thinning that reduces the radiative cooling flux by $5 \%$. In our simulations, all the top-sheared cases reduce the LWP and weaken the radiative flux more than $5 \%$ when compared to the $000 \mathrm{U}$ case (see Table 1, where we report the difference of $\Delta F_{\text {rad }}=F_{\text {rad }}\left(z_{i}\right)-F_{\text {rad }}\left(z_{b}\right)$, the net longwave radiative flux 
Table 1

Resulting Parameters for the Different Cases Averaged From 3:45-4:00 $\mathrm{h}$

\begin{tabular}{|c|c|c|c|c|c|c|c|c|c|c|c|c|}
\hline & Units & CTRL & $075 \mathrm{U}$ & $050 \mathrm{U}$ & $025 \mathrm{U}$ & $000 \mathrm{U}$ & CTRL-S5 & CTRL-S10 & 050U-S5 & 050U-S10 & 000U-S5 & 000U-S10 \\
\hline$z_{i}$ & $\mathrm{~m}$ & 870 & 871 & 870 & 868 & 869 & 867 & 864 & 868 & 864 & 868 & 868 \\
\hline$z_{b}$ & $\mathrm{~m}$ & 666 & 665 & 658 & 651 & 653 & 672 & 680 & 675 & 686 & 686 & 685 \\
\hline$h$ & $\mathrm{~m}$ & 205 & 206 & 212 & 217 & 216 & 196 & 184 & 193 & 177 & 183 & 182 \\
\hline$w_{e}$ & $\mathrm{~mm} / \mathrm{s}$ & 4.82 & 4.99 & 4.87 & 4.86 & 4.83 & 4.19 & 5.11 & 4.36 & 4.42 & 4.95 & 5.24 \\
\hline$w_{*}$ & $\mathrm{~m} / \mathrm{s}$ & 0.84 & 0.83 & 0.82 & 0.81 & 0.81 & 0.84 & 0.84 & 0.82 & 0.82 & 0.81 & 0.81 \\
\hline$w_{*, \mathrm{cld}}$ & $\mathrm{m} / \mathrm{s}$ & 0.57 & 0.59 & 0.62 & 0.63 & 0.64 & 0.52 & 0.50 & 0.54 & 0.49 & 0.55 & 0.55 \\
\hline$u_{*}$ & $\mathrm{~m} / \mathrm{s}$ & 0.32 & 0.25 & 0.18 & 0.11 & 0.01 & 0.30 & 0.31 & 0.17 & 0.19 & 0.03 & 0.05 \\
\hline$u_{*, \text { top }}$ & $\mathrm{m} / \mathrm{s}$ & 0.07 & 0.05 & 0.05 & 0.04 & 0.04 & 0.16 & 0.24 & 0.15 & 0.22 & 0.14 & 0.22 \\
\hline$\Delta r$ & $\mathrm{~m} / \mathrm{s}$ & 0.10 & 0.06 & 0.02 & 0.002 & 0.02 & 5.7 & 10.4 & 5.0 & 9.7 & 4.8 & 9.3 \\
\hline$\Delta r / w_{*, \mathrm{cld}}$ & - & 0.18 & 0.09 & 0.03 & 0.004 & 0.03 & 10.9 & 20.8 & 9.4 & 19.9 & 8.7 & 16.9 \\
\hline$L_{\mathrm{ob}}$ & $\mathrm{m}$ & -121 & -61.7 & -24.1 & -5.45 & -0.001 & -95.8 & -105 & -21.2 & -24.8 & -0.11 & -0.53 \\
\hline$H$ & - & 7.18 & 14.1 & 36 & 159 & 653,850 & 9.05 & 8.25 & 40.9 & 34.7 & 7,679 & 1,630 \\
\hline$\Delta F_{\mathrm{rad}}$ & $\%$ & 90.2 & 92.3 & 95.1 & 97.0 & 100 & 86.1 & 83.8 & 88.1 & 82.0 & 87.7 & 91.0 \\
\hline$\Delta F_{\text {rad,000U }}$ & & & & & & & & & & & & \\
\hline
\end{tabular}

divergence between the STBL top and mean cloud base). A possible cause of depletion occurring below the proposed threshold of $10 \mathrm{~m} \mathrm{~s}^{-1}$ is that Schulz and Mellado (2018) assumed an adiabatic profile for $q_{l}(z)$ for the derivation of the threshold, while in fact our simulations show that top shear causes the $q_{l}(z)$ profile to be sub-adiabatic (Figure 4e).

\subsection{Spatial Organization of the STBL}

A first glimpse at the behavior of LWP and vertical velocity in the domain shows a distinct spatial structure and features when varying surface and top wind shear (Figures 5 and 6). In the 000U case without surface and top shear, updrafts develop as plumes, displaying a network-like cellular organization in the regions where they form and a solid cohesive form in the regions where they fully develop and terminate. In contrast, in the strongly sheared CTRL case, subcloud roll structures appear (white aligned areas). We will see that this behavior is captured in the updraft and downdraft object identification in the next Section. In a CBL, the transition between cells and rolls occurs for $\eta \simeq 15-20$ (Salesky et al., 2017), which is in agreement with our simulations: only the CTRL $(\eta=7.2)$ case and in a lesser degree the 075U $(\eta=14.1)$ case show evidence of rolls (Figure 5 and Table 1). We further calculate a roll factor $\mathcal{R}$ (Salesky et al., 2017),

$$
\mathcal{R}(z)=\max _{r_{\rho}}\left[\left\{\max _{r_{\theta}}\left[R_{w w}\left(r_{\rho}, r_{\theta}, z\right)\right]-\min _{r_{\theta}}\left[R_{w w}\left(r_{\rho}, r_{\theta}, z\right)\right]\right\} \mid r_{\rho} / z_{i} \geq 0.5\right],
$$

where $R_{w w}$ is the spatial autocorrelation of the vertical velocity in polar coordinates ( $\rho$ and $\theta$ are the radial and angular directions, and $r_{\rho}$ and $r_{\theta}$ are radial and angular lags), at each vertical level. The roll factor $\mathcal{R}$ is higher when there are rolls present, with a theoretical maximum of 2 for a perfect line pattern. Figure 7 confirms that the CTRL, CTRL-S5, and CTRL-S10 cases have a distinctly higher $\mathcal{R}$ in the subcloud region.

For strong top shear, the flow near the top does not develop the same type of streaky structures as near the surface, since the stratified shear layer dynamics are different than those over a wall (Pham et al., 2009). The cellular shape near the top shows weaker negative velocities when the top shear is strong (visible as darker cell edges when comparing the circled region $\mathrm{C} 1$ in Figures 5 and 6), and better alignment in the direction of the wind shear. This is also reflected in the shape of the clouds when looking at LWP (top row), with a regular cellular pattern in most cases and cloud elements aligning in the direction of the wind strongly for the CTRL-S10 case, and more weakly for the 050U-S10 case. This suggests that both strong surface and top shear are necessary to influence the shape of the cloud field. However, the roll factor in the cloud region, 

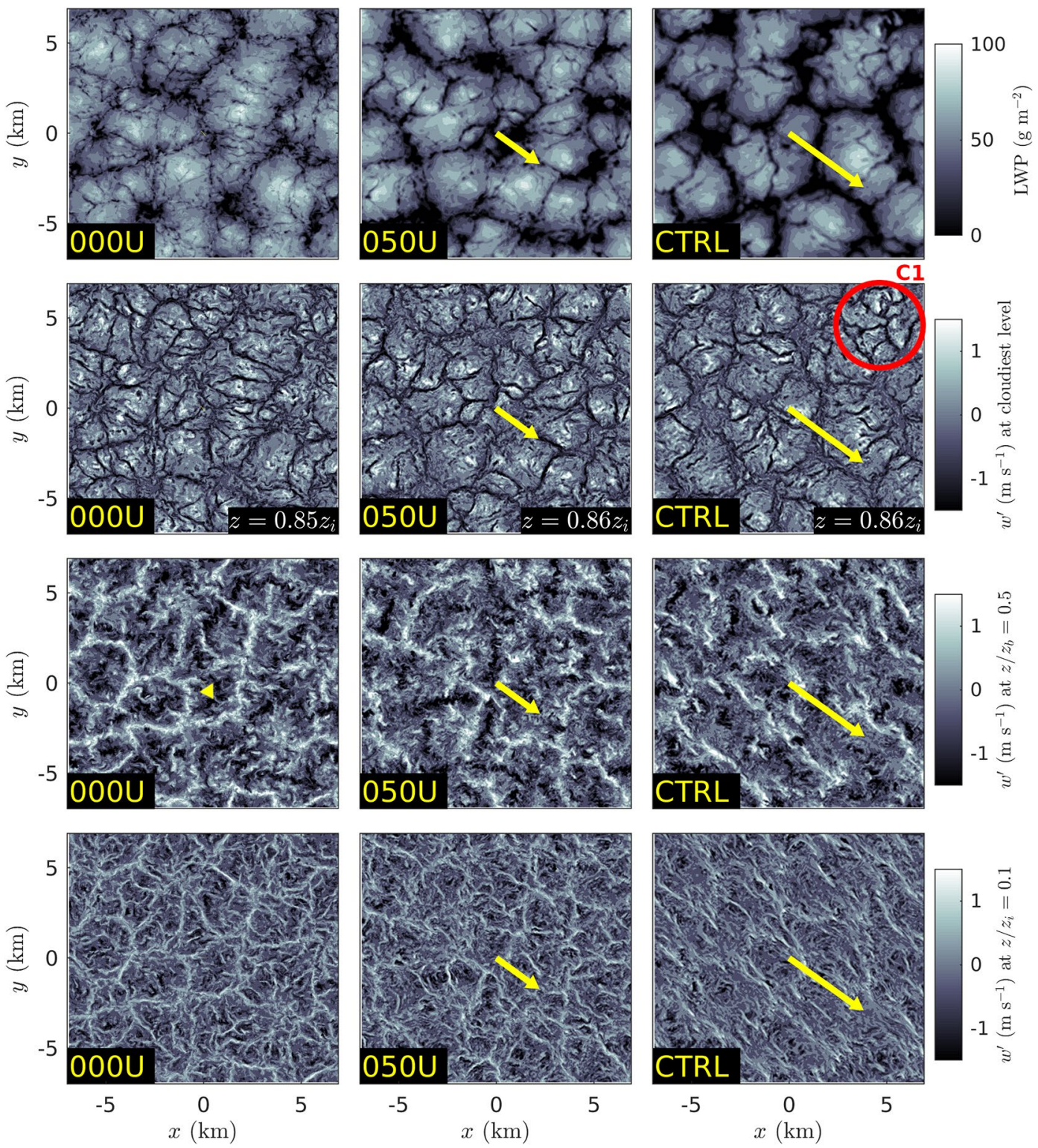

Figure 5. Spatial snapshots at hour 4 for the cases with no top shear. LWP (top row) and vertical velocity near the surface $\left(z=0.1 z_{i}\right.$, bottom row), in the subcloud region $\left(z=0.5 z_{b}\right.$, second row), and in the cloud region (at the height of maximum cloud fraction, third row). The circled region $\mathrm{C} 1$ marks features of vertical velocity that are referenced in the text. Yellow arrows show the mean velocity vector at each height, where the arrow magnitude in $\mathrm{m} \mathrm{s}^{-1}$ corresponds to $\mathrm{km}$ in the spatial scale. LWP, liquid water path.

between $0.75 z_{i}$ and $0.98 z_{i}$, shows a similar $\mathcal{R}$ (Figure 7), meaning that even for clouds that show alignment, the cellular structure is strongly present. Downdraft regions display a network-like structure near the top of the STBL, but upon entering the subcloud region, downdraft regions transition into occupying the gaps left by the updrafts.

Figure 8 shows the cloud top height $z_{t}$ field (the last height at which we encounter liquid water), where the strongly top-sheared cases (bottom row) present signs of gravity waves. The observed wavelength in the $z_{t}$ field is of the order of $1 \mathrm{~km}$, which matches the Kelvin-Helmholtz instability theory for combined buoyancy and shear (Drazin, 2002). According to the theory, the critical wavelength is $\lambda=\frac{\pi \theta_{v 0} \Delta r^{2}}{g \Delta \theta_{v}}$, where $\Delta r$ and $\Delta \theta_{v}$ are the initial values of the wind speed magnitude jump and virtual potential temperature jump across the 

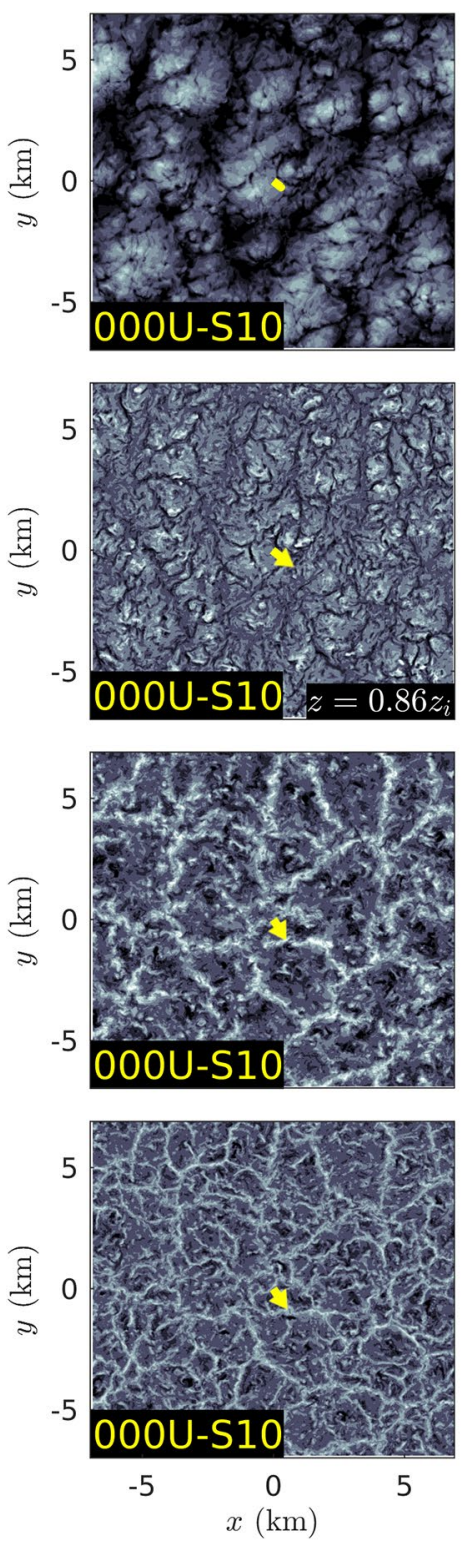
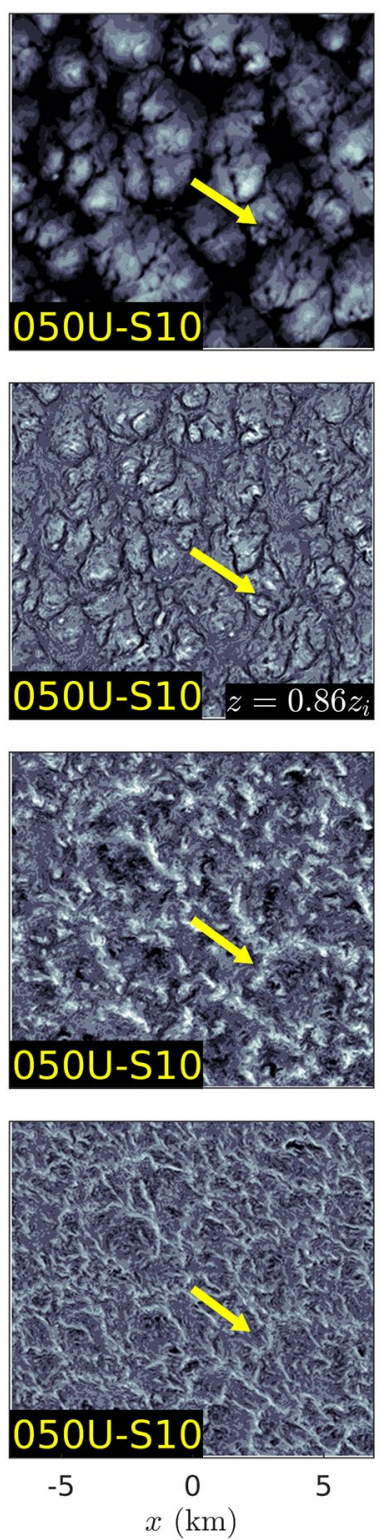
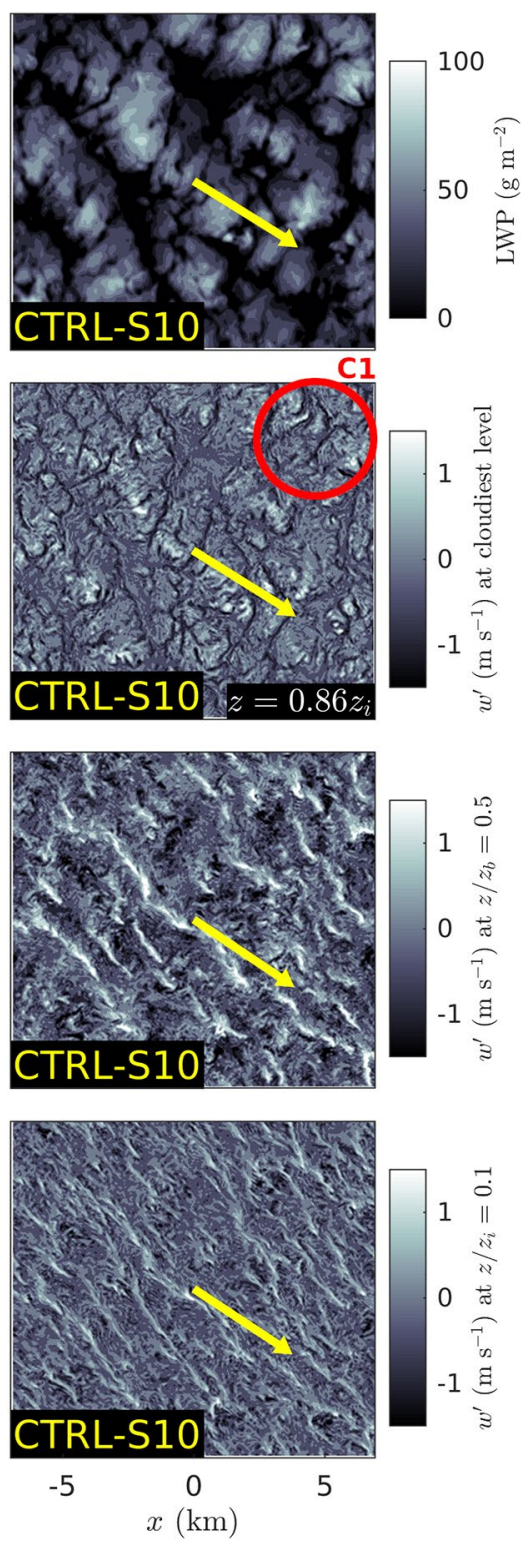

Figure 6. Spatial snapshots at hour 4 for strongly top sheared cases. LWP (top row) and vertical velocity near the surface $\left(z=0.1 z_{i}\right.$, bottom row), in the subcloud region $\left(z=0.5 z_{b}\right.$, second row), and in the cloud region (at the height of maximum cloud fraction, third row). The circled region $\mathrm{C} 1$ marks features of vertical velocity that are referenced in the text. Yellow arrows show the velocity vector at each height, where the arrow magnitude in $\mathrm{m} \mathrm{s}^{-1}$ corresponds to km in the spatial scale. LWP, liquid water path.

inversion region. For strong top shear (the S10 cases), $\lambda=1.28 \mathrm{~km}$ (yellow pattern in Figure 8), agrees with the pattern seen at $z_{t}$. Meanwhile, for weaker top shear (S5 cases), the expected $\lambda=312 \mathrm{~m}$ is not observed in $z_{t}$ for our simulations. The chosen LES grid spacing should be able to capture the gravity waves, although not with great resolution; $\Delta x=35 \mathrm{~m}$ places 6 points within a wave period of $300 \mathrm{~m}$ oriented at a $45^{\circ}$ angle, while the observed shear layer of thickness $\mathrm{O}(30 \mathrm{~m})$ would also be resolved by 6 points in the vertical. There could also be a critical length scale for waves to affect the cloud top; more top-shear cases would need to be analyzed to confirm this hypothesis. Nevertheless, gravity waves shaping the cloud top enhance the variability of LWP. The gravity wave signature is also observed in the vertical velocity field, as evidenced by high roll factors in the inversion region (Figure 7), which also show a stronger alignment for the S10 cases than the S5 cases, and a growth of the inversion region with top shear, agreeing with Figure 4. 


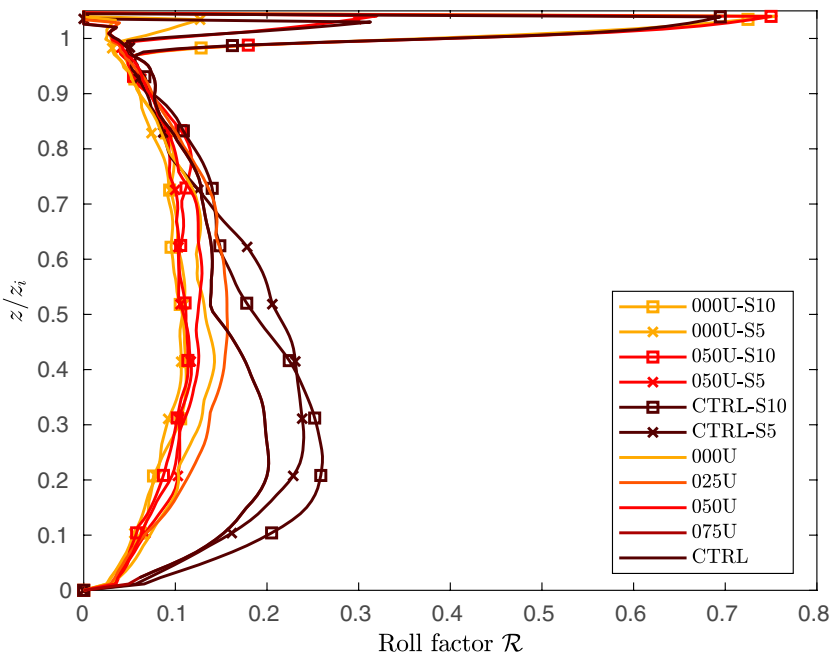

Figure 7. Vertical profiles of the roll factor $\mathcal{R}$ calculated at hour 4 .

\subsection{Updraft and Downdraft Objects}

\subsubsection{Spatial Distribution and Geometric Properties}

Figure 9 shows a three-dimensional visualization of the objects identified as tall (categories I and II) for the cases CTRL and 000U, with detailed views of portions of updraft and downdraft objects for each case. Surface shear changes the vertical inclination of the updraft objects while the downdraft objects are not inclined. Updraft objects are typically connected to the surface and can split into separate branches higher up in the STBL. Conversely, downdrafts may split while moving into the subcloud layer. The network structure mentioned in the previous section is not observed in the tall objects. Tall updraft objects organize in the direction of the wind for the CTRL case, which gives rise to the overall roll structure in the STBL.

Figure 10 shows the distribution of the different objects within the STBL by their assigned category for the cases CTRL and CTRL-S10. The general distribution of the objects is similar for all cases. One difference is the reduction of top small objects (VI) with stronger top shear. Tall and thick updraft and downdraft objects (category I) tend to reach the top of the STBL. The number of tall thick objects is small, but generally, there are
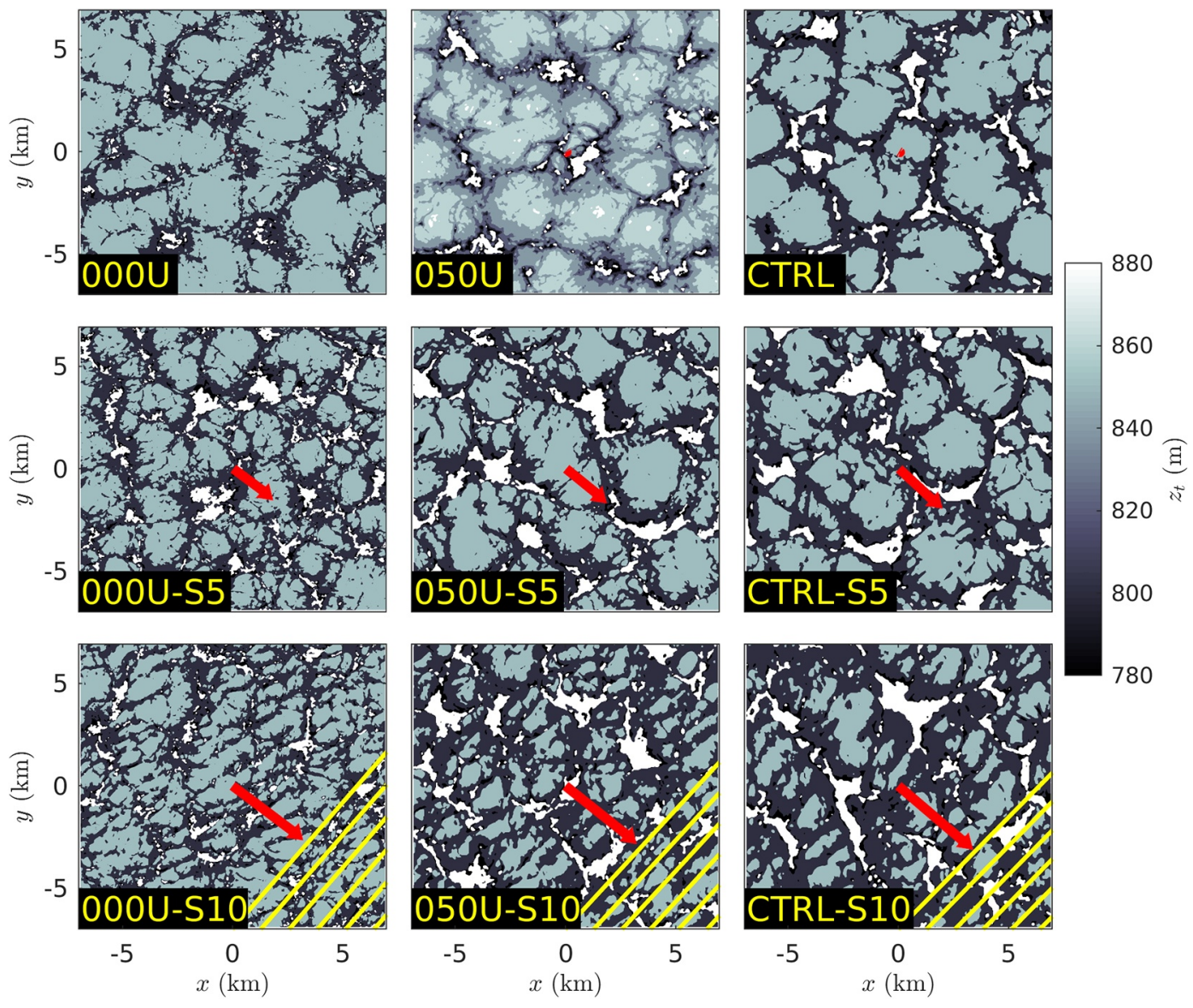

Figure 8. Spatial snapshot of cloud top heights (last height with liquid water content) for different cases at hour 4. Yellow lines mark the theoretical wavelength pattern expected for the strongly sheared cases and red arrows mark the wind speed jump across the inversion region, where the arrow magnitude in $\mathrm{m} \mathrm{s}^{-1}$ corresponds to $\mathrm{km}$ in the spatial scale. Colormap limits do not cover the full range of observed values to enhance the visual contrast. 

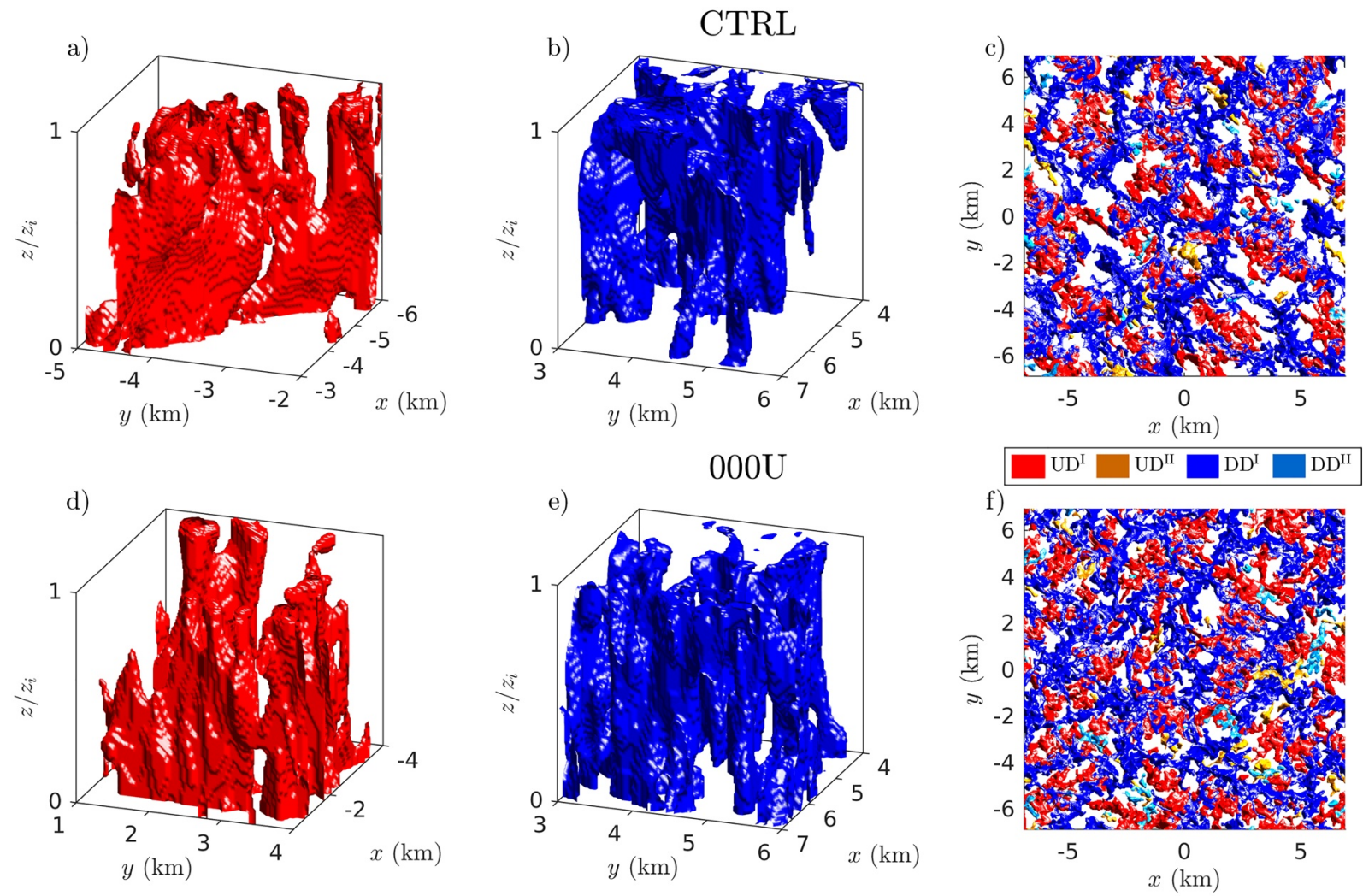

Figure 9. Three-dimensional visualization of identified large updraft and downdraft objects in the CTRL (top row), 000U (second row) cases: left panels (a), (d) show details of a tall updraft object, middle panels (b), (e) show a tall downdraft object, and right panels (c), (f) show the top view of all tall updraft and downdraft objects identified in the full domain.

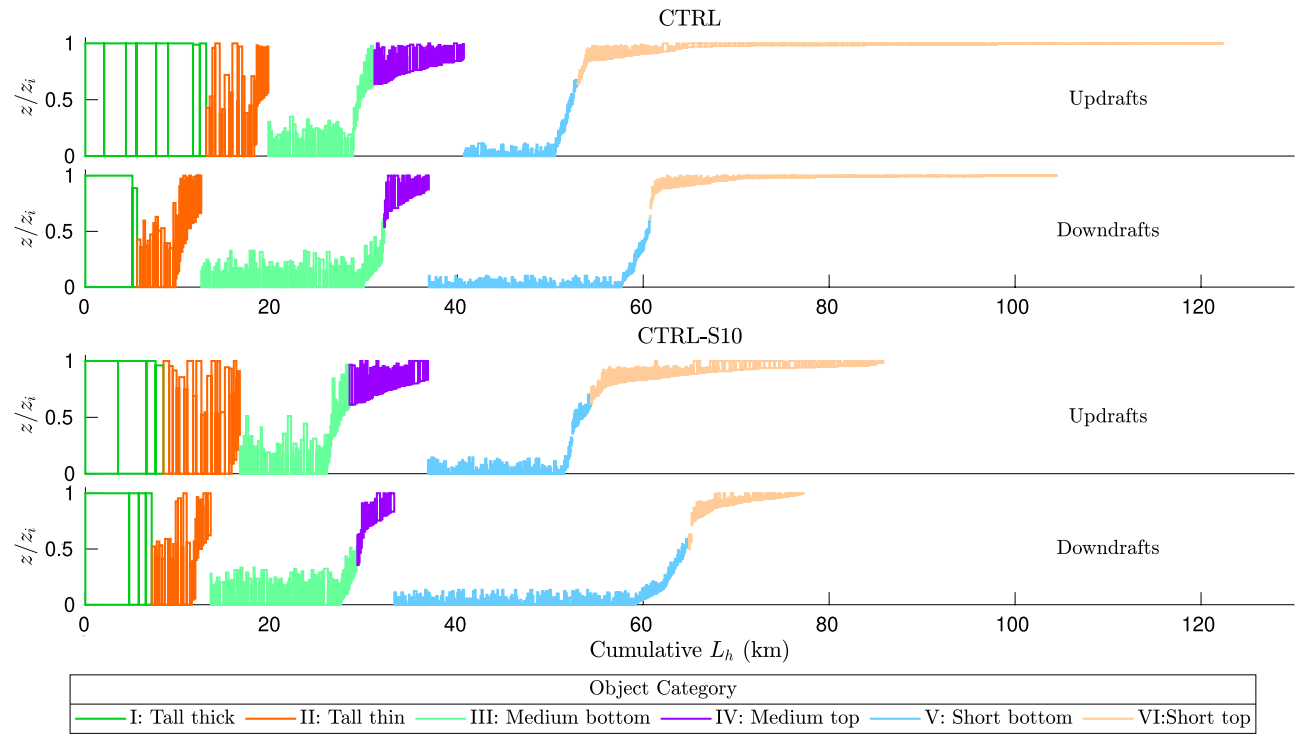

Figure 10. Distribution of updrafts and downdraft objects by case, where each bar represents an object. The different categories are labeled by color, and each object is described by its vertical position and horizontal length $L_{h}$, representing its occupied space in the horizontal direction. Objects I and II correspond to tall objects spanning the whole STBL separated into thicker and thinner objects, III and IV are medium objects separated by their origin into bottom and top objects, and V and VI are short objects also separated into bottom and top objects. STBL, Stratocumulus topped boundary layers. 

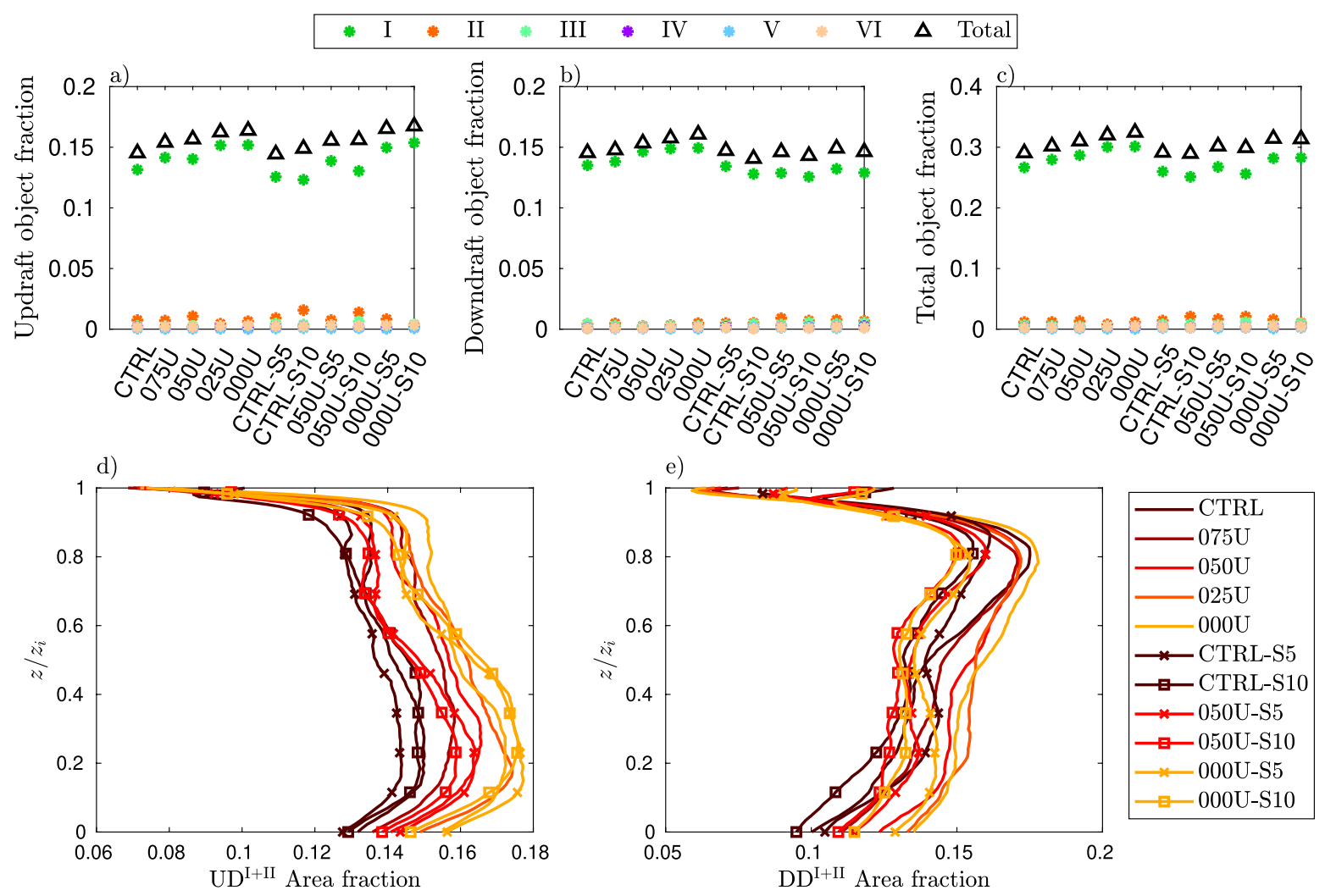

Figure 11. Volume fractions per object type in the STBL for (a) updrafts, (b) downdrafts, and (c) total of updrafts and downdrafts. Area fractions as a function of height for the tall (I and II) (d) updrafts and (e) downdrafts. STBL, Stratocumulus topped boundary layers.

more updraft than downdraft objects for the cases without top shear. Medium and small objects are mostly occupying the surface and top regions, meaning that in the middle of the STBL, updraft and downdraft portions are usually contained in tall objects. Even though we observed early signs of decoupling for the 000U-S10 case in Figure 4, there is no manifestation of decoupling in the distribution of updraft and downdraft objects, as a similar number of tall objects span the whole STBL. This characterization of the object distribution in space could be a useful tool to compare object detection methods in other settings.

The volume occupied by updrafts and downdrafts combined reaches $30 \%$ of the total STBL (Figure 11c), with only the tall objects (I and II) having a significant volume fraction. Updrafts always occupy more space than downdrafts, and both updraft and downdraft volume fractions decrease with top shear. Across the STBL, the area fraction of the tall objects is also affected by changes in shear: while stronger surface shear diminishes the updraft area fraction, stronger top shear diminishes the downdraft area fraction throughout the STBL (Figures 11d and 11e).

\subsubsection{Contribution to Turbulent Fluxes}

Updrafts and downdrafts contribute significantly to turbulent fluxes. We compute the contributions by conditionally sampling the covariance contained in each of the different categories of objects (I to VI), finding that the tall objects (I and II) contribute the most, as expected because of their larger volume fraction. Figures 13h-13l show the mean ratios $R_{w^{\prime} w^{\prime}}, R_{w^{\prime} \theta_{v}^{\prime}}, R_{w^{\prime} q_{t}^{\prime}}, R_{w^{\prime} \theta_{l}}$, and $R_{F_{r}}$, computed as vertical averages of the portion of total turbulent fluxes (including the subgrid fluxes) explained by the tall objects (I and II), for all cases. On average, $65 \%$ of the total vertical velocity variance $\overline{w^{\prime} w^{\prime}}, 83 \%$ of the total buoyancy flux, and $79 \%$ of the net momentum flux are contained in the tall objects (I and II). The contribution of tall downdrafts (I and II) to $\overline{w^{\prime} w^{\prime}}$ weakens with stronger top-shear (Figure 12a), which can be explained by the reduced cloud fraction and radiative cooling caused by the enhanced top mixing. This is demonstrated when comparing the CTRL, 

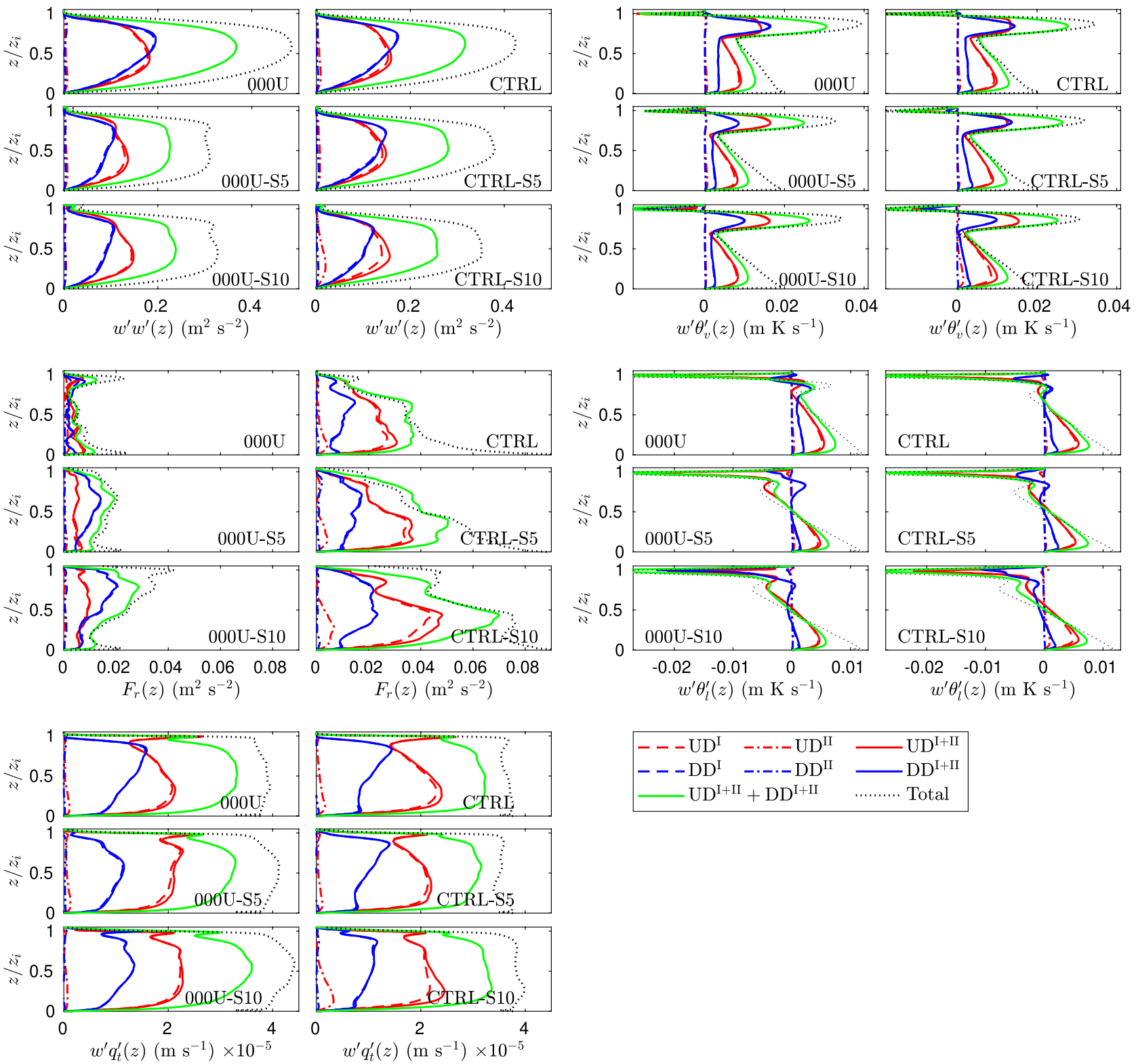

Figure 12. Contribution of the tall updraft and downdraft object categories (I and II) to (a) vertical velocity variance $w^{\prime} w^{\prime}$, (b) buoyancy flux $w^{\prime} \theta_{v}{ }^{\prime}$, (c) net horizontal momentum flux $F_{r}$, (d) heat flux $w^{\prime} \theta_{l}{ }^{\prime}$, and (e) moisture flux $w^{\prime} q_{t}{ }^{\prime}$. Dashed black lines show the total fluxes contained in the domain, including subgrid fluxes.

CTRL-S5, and CTRL-S10 cases: while the updraft contribution remains identical, the downdraft portion decreases with stronger top shear, causing an overall reduction of $\overline{w^{\prime} w^{\prime}}$. The mean vertical velocity of the $\mathrm{UD}^{I}$ and $\mathrm{DD}^{I}$ objects also decreases with top-shear (not shown), with downdraft velocities weakening more than updrafts. For the total $\overline{w^{\prime} q_{t}^{\prime}}$, the tall objects (I and II) account for $77 \%$ of the fluxes, on average, and for $\overline{w^{\prime} \theta_{l}^{\prime}}$, tall objects account for $36 \%$. For both $\overline{w^{\prime} q_{t}^{\prime}}$ and $\overline{w^{\prime} \theta_{l}^{\prime}}$, updrafts dominate the contributions, while for the momentum flux $F_{r}$, downdrafts dominate when only top shear is present (Figure 12c).

Some of these ratios can be misleading, as (1) they are vertical averages; (2) the $\overline{w^{\prime} \theta_{l}^{\prime}}$ and $\overline{w^{\prime} \theta_{v}^{\prime}}$ profiles change sign; (3) ratios of small values are not accurate and have been omitted in the vertical averaging; and (4) some profiles do not change sign but large objects can have local contributions that exceed the total flux (such is the case of CTRL-S5 for $F_{r}$ ). Instead, the complete picture of the contributions in Figure 12 should be used 

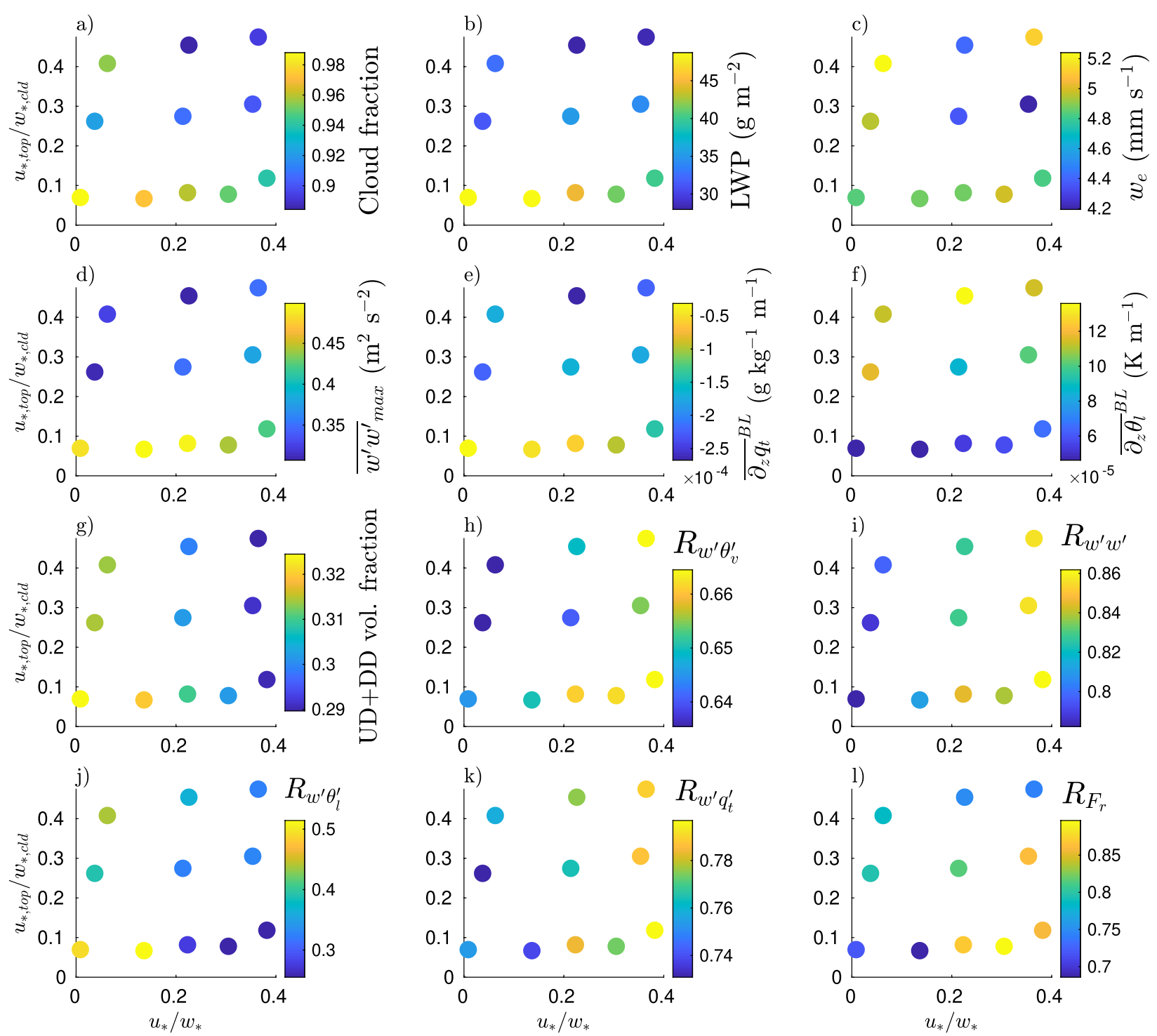

Figure 13. Summarized results at hour 4, presented in the parameter space of surface wind shear $u_{*} / w_{*}$ and top wind shear $u_{*, t o p} / w_{*, c l d}$ for (a) cloud fraction, (b) LWP, (c) entrainment rate $w_{e}$, (d) maximum velocity variance $\overline{w^{\prime} w^{\prime}}$ max , (e) the mean slope of $q_{t}$ between $0.2 z_{i}$ and $0.8 z_{i}, \bar{\partial}_{z} q_{t}{ }^{\mathrm{BL}}$, (f) the mean slope of $\theta_{l}$ between $0.2 z_{i}$ and $0.8 z_{i}, \bar{\partial}_{z} \theta_{l}$ BL,$(\mathrm{g})$ tall draft object volume fraction in the STBL (updrafts and downdrafts, I and II objects); mean contributions of all the tall draft objects to the (h) vertical velocity variance $R_{w^{\prime} w^{\prime}}$, (i) buoyancy flux $R_{w^{\prime} \theta_{v}^{\prime}}$, (j) heat flux $R_{w^{\prime} \theta_{l}^{\prime}}$, (k) moisture flux $R_{w^{\prime} q_{t}^{\prime}}$, and (l) net horizontal momentum flux $R_{F_{r}}$. LWP, liquid water path; STBL, Stratocumulus topped boundary layers.

for interpretation. The challenges in computing the tall object contributions may explain why we obtain different values for heat fluxes than Brient et al. (2019), who reported $75 \%$ for moisture and $79 \%$ for heat fluxes. Other reasons include the use of a different base case and intrinsic differences in their tracer methodology and parameter selection. While there are known differences in the detection of updraft and downdraft regions between tracer and field variable methods (Couvreux et al., 2010), these differences are expected to be greater in the surface and top regions. Even in the middle of the STBL, the updraft and downdraft contribution is smaller in our case. Aside from contributions, Figure 12b shows an interesting behavior of the downdrafts in the subcloud buoyancy flux, with nearly constant profiles for the cases with no surface shear. This may be due to weak mixing of the downdrafts with the environment, and it could be related to how the cell or roll organization impacts the descent of downdrafts. 
A summary of the effect of wind shear conditions on different properties of the STBL is shown in Figure 13. First, cloud fraction and LWP are sensitive to both surface and top wind shear (Figures 13a and 13b), with a general trend of less clouds with increased surface and top wind shear. As discussed previously, the trend of entrainment rate is not clear in the cases studied (Figure 13c) even though there is evidence of increased mixing in the growth of the inversion region. We also observe a decrease in vertical velocity variance with surface and top shear (Figure 13d), where interestingly the maximum velocity variance $\overline{w^{\prime} w^{\prime}}$ max is strongly correlated to LWP (correlation coefficient of 95\%). The vertical profiles of moisture and temperature were also strongly affected by shear; Figures $13 \mathrm{e}$ and $13 \mathrm{f}$ show the mean slope of $q_{t}$ and $\theta_{l}$ calculated between $0.2 z_{i}$ and $0.8 z_{i}$, with well-mixed conditions prevailing for weaker surface and weaker top shear. Another interesting finding is that the total volume fraction of all the updraft and downdraft objects is sensitive to shear conditions; moreover, this dependence strongly correlates to $\overline{w^{\prime} w^{\prime}}$ max due to their definition depending on vertical velocity (corr. coef. of 97\%). Lastly, the contributions of the tall (I and II) updraft and downdraft objects to the total turbulent fluxes in the STBL are also affected by both surface and top wind shear in different ways, with only the mean ratio $R_{w^{\prime}} q_{t}^{\prime}$ independent of top wind shear (Figures 13h-13l). Further studies on understanding the variations of the turbulent flux contributions could be helpful for improving turbulence parameterizations.

\section{Conclusions}

We analyzed the effect of surface and top wind shear on the spatial organization of a Stratocumulus-topped boundary layer. We used LES simulations of the DYCOMS II RF01 base case with wind profile variations. We also performed a spatial identification of coherent updrafts and downdrafts, classified them by location and size distribution, and described how they are affected by shear.

Surface shear affects the spatial organization of the clouds as well as the vertical profiles that characterize the STBL. Weak surface shear organizes the updrafts in plume-like structures while strong surface shear creates rolls. The former causes strongly well-mixed thermodynamic profiles that result in an increased cloud fraction and LWP. Rolls are observed for values of $-z_{i} / L_{o b}<15$, in agreement with the transition for CBLs (Salesky et al., 2017). The effect of weaker surface shear is opposite to the reduced cloud fraction for shallow cumulus clouds (Park et al., 2017).

Stronger top shear also decreases cloud fraction and LWP by thinning the cloud from the top, as expected from previous studies (Schulz \& Mellado, 2018; Wang et al., 2012). Cloud thinning also weakens the downdraft contribution to the turbulent fluxes, with indications of early decoupling observed for the cases with stronger top than surface shear. Gravity waves were also observed for strong top shear, shaping the top of the cloud layer and flow near the inversion region. Combined strong surface and top wind shear caused the clouds to be elongated in the direction of the mean wind.

Classifying the updraft and downdraft objects by size and position shows that objects that span the whole STBL dominate in terms of volume and are responsible for a large portion of the turbulent fluxes, explaining, on average for all cases, $65 \%$ of the total vertical velocity variance and $83 \%$ of the total buoyancy flux. This confirms a classic assumption used in the development of turbulence parameterizations, of largest eddies contributing the most to turbulent fluxes (Randall et al., 1992), and suggests that coarser resolution models can resolve a significant part of the turbulent fluxes. When surface shear is strong, updrafts tilt in the direction of the wind, and updrafts and downdrafts connect in the mean wind direction. When top shear is strong, the enhanced mixing reduces cloud fraction near the STBL top.

Future work should examine other definitions of updrafts and downdrafts, other realistic conditions that can affect the organization of coherent structures in the STBL, as well as understanding the dynamics of these coherent structures during the course of the day or along Lagrangian trajectories.

\section{Data Availability Statement}

The code used for the analysis is available at https://doi.org/10.5281/zenodo.4116253. 
Acknowledgments

The authors thank Elynn Wu and José Ortíz Tarín for helpful discussion and comments. M. Zamora Zapata was funded by CONICYT PFCHA/DOCTORADO BECAS CHILE/2015-72160605. T. Heus was supported by the U.S. Department of Energy's Atmospheric System Research, an Office of Science, Office of Biological and Environmental Research program, under Grant DE-SC0017999. The authors declare no conflict of interest.

\section{References}

Atkinson, B. W., \& Wu Zhang, J. (1996). Mesoscale shallow convection in the atmosphere. Reviews of Geophysics, 34(4), 403-431. https:// doi.org/10.1029/96RG02623

Brient, F., Couvreux, F., Villefranque, N., Rio, C., \& Honnert, R. (2019). Object-oriented identification of coherent structures in large eddy simulations: Importance of downdrafts in stratocumulus. Geophysical Research Letters, 46(5), 2854-2864. https://doi. org/10.1029/2018GL081499

Chinita, M. J., Matheou, G., \& Teixeira, J. (2018). A Joint probability density-based decomposition of turbulence in the atmospheric boundary layer. Monthly Weather Review, 146(2), 503-523. https://doi.org/10.1175/MWR-D-17-0166.1

Clemesha, R. E. S., Gershunov, A., Iacobellis, S. F., \& Cayan, D. R. (2017). Daily variability of California coastal low cloudiness: A balancing act between stability and subsidence. Geophysical Research Letters, 44(7), 3330-3338. https://doi.org/10.1002/2017GL073075

Couvreux, F., Hourdin, F., \& Rio, C. (2010). Resolved versus parametrized boundary-layer plumes. Part I: A parametrization-oriented conditional sampling in large-eddy simulations. Boundary-Layer Meteorology, 134(3), 441-458. https://doi.org/10.1007/s10546-009-9456-5

Davini, P., D’Andrea, F., Park, S.-B., \& Gentine, P. (2017). Coherent structures in large-eddy simulations of a nonprecipitating stratocumulus-topped boundary layer. Journal of the Atmospheric Sciences, 74(12), 4117-4137. https://doi.org/10.1175/JAS-D-17-0050.1

Drazin, P. G. (2002). Introduction to hydrodynamic stability. Cambridge University Press. https://doi.org/10.1017/CBO9780511809064

Faloona, I., Lenschow, D. H., Campos, T., Stevens, B., van Zanten, M., Blomquist, B., et al. (2005). Observations of entrainment in eastern Pacific marine stratocumulus using three conserved scalars. Journal of the Atmospheric Sciences, 62(9), 3268-3285. https://doi. org/10.1175/JAS3541.1

Fedorovich, E., \& Conzemius, R. (2008). Effects of wind shear on the atmospheric convective boundary layer structure and evolution. Acta Geophysica, 56(1), 114-141. https://doi.org/10.2478/s11600-007-0040-4

Ghonima, M. S., Heus, T., Norris, J. R., \& Kleissl, J. (2016). Factors controlling stratocumulus cloud lifetime over coastal land. Journal of the Atmospheric Sciences, 73(8), 2961-2983. https://doi.org/10.1175/JAS-D-15-0228.1

Han, J., \& Bretherton, C. S. (2019). TKE-based moist Eddy-Diffusivity Mass-Flux (EDMF) parameterization for vertical turbulent mixing. Weather and Forecasting, 34(4), 869-886. https://doi.org/10.1175/WAF-D-18-0146.1

Kim, S.-W., Park, S.-U., \& Moeng, C.-H. (2003). Entrainment processes in the convective boundary layer with varying wind shear. Boundary-Layer Meteorology, 108(2), 221-245. https://doi.org/10.1023/A:1024170229293

Kopec, M. K., Malinowski, S. P., \& Piotrowski, Z. P. (2016). Effects of wind shear and radiative cooling on the stratocumulus-topped boundary layer. Quarterly Journal of the Royal Meteorological Society, 142(701), 3222-3233. https://doi.org/10.1002/qj.2903

Lilly, D. K. (1968). Models of cloud-topped mixed layers under a strong inversion. Quarterly Journal of the Royal Meteorological Society, 94(401), 292-309. https://doi.org/10.1002/qj.49709440106

Lin, C. L., McWilliams, J. C., Moeng, C. H., \& Sullivan, P. P. (1996). Coherent structures and dynamics in a neutrally stratified planetary boundary layer flow. Physics of Fluids, 8(10), 2626-2639. https://doi.org/10.1063/1.869048

Matheou, G., \& Teixeira, J. (2019). Sensitivity to physical and numerical aspects of large-eddy simulation of stratocumulus. Monthly Weather Review, 147(7), 2621-2639. https://doi.org/10.1175/MWR-D-18-0294.1

McMichael, L. A., Mechem, D. B., Wang, S., Wang, Q., Kogan, Y. L., \& Teixeira, J. (2019). Assessing the mechanisms governing the daytime evolution of marine stratocumulus using large-eddy simulation. Quarterly Journal of the Royal Meteorological Society, 145(719), 845-866. https://doi.org/10.1002/qj.3469

Mellado, J. P., Stevens, B., \& Schmidt, H. (2014). Wind shear and buoyancy reversal at the top of stratocumulus. Journal of the Atmospheric Sciences, 71(3), 1040-1057. https://doi.org/10.1175/JAS-D-13-0189.1

Moeng, C.-H., \& Sullivan, P. P. (1994). A comparison of shear- and buoyancy-driven planetary boundary layer flows. Journal of the Atmospheric Sciences, 51(7), 999-1022. 10.1175/1520-0469(1994)051<0999:acosab>2.0.co;2

NOAA. (2021). National data buoy center - station 46025 - climatic summary plots for wind speed. Retrieved 2021-01-11, from https://www. ndbc.noaa.gov/view_climplot.php?station $=46025 \&$ meas $=$ ws

Park, S.-B., \& Baik, J.-J. (2014). Large-Eddy Simulations of Convective Boundary Layers over Flat and Urbanlike Surfaces. Journal of the Atmospheric Sciences, 71(5), 1880-1892. Retrieved from https://doi.org/10.1175/jas-d-13-0191.1

Park, S.-B., Böing, S., \& Gentine, P. (2018). Role of surface friction on shallow nonprecipitating convection. Journal of the Atmospheric Sciences, 75(1), 163-178. https://doi.org/10.1175/JAS-D-17-0106.1

Park, S.-B., Gentine, P., Schneider, K., \& Farge, M. (2016). Coherent Structures in the boundary and cloud layers: Role of updrafts, subsiding shells, and environmental subsidence. Journal of the Atmospheric Sciences, 73(4), 1789-1814. https://doi.org/10.1175/JAS-D-15-0240.1

Pedersen, J. G., Malinowski, S. P., \& Grabowski, W. W. (2016). Resolution and domain-size sensitivity in implicit large-eddy simulation of the stratocumulus-topped boundary layer. Journal of Advances in Modeling Earth Systems, 8(2), 885-903. https://doi. org/10.1002/2015MS000572

Pham, H. T., Sarkar, S., \& Brucker, K. A. (2009). Dynamics of a stratified shear layer above a region of uniform stratification. Journal of Fluid Mechanics, 630, 191-223. https://doi.org/10.1017/S0022112009006478

Randall, D. A., Shao, Q., \& Moeng, C.-H. (1992). A second-order bulk boundary-layer model. Journal of the Atmospheric Sciences, 49(20), 1903-1923. https://doi.org/10.1175/1520-0469(1992)049〈1903:ASOBBL〉2.0.CO;2

Salesky, S. T., Chamecki, M., \& Bou-Zeid, E. (2017). On the nature of the transition between roll and cellular organization in the convective boundary layer. Boundary-Layer Meteorology, 163(1), 41-68. https://doi.org/10.1007/s10546-016-0220-3

Schulz, B., \& Mellado, J. P. (2018). Wind shear effects on radiatively and evaporatively driven stratocumulus tops. Journal of the Atmospheric Sciences, 75(9), 3245-3263. https://doi.org/10.1175/JAS-D-18-0027.1

Stevens, B., Moeng, C.-H., Ackerman, A. S., Bretherton, C. S., Chlond, A., de Roode, S., et al. (2005). Evaluation of large-eddy simulations via observations of nocturnal marine stratocumulus. Monthly Weather Review, 133(6), 1443-1462. https://doi.org/10.1175/MWR2930.1

Wang, S., Golaz, J.-C., \& Wang, Q. (2008). Effect of intense wind shear across the inversion on stratocumulus clouds. Geophysical Research Letters, 35(15). https://doi.org/10.1029/2008GL033865

Wang, S., Zheng, X., \& Jiang, Q. (2012). Strongly sheared stratocumulus convection: An observationally based large-eddy simulation study. Atmospheric Chemistry and Physics, 12(11), 5223-5235. https://doi.org/10.5194/acp-12-5223-2012

Wood, R. (2012). Stratocumulus clouds. Monthly Weather Review, 140(8), 2373-2423. https://doi.org/10.1175/MWR-D-11-00121.1 
Wu, E., Yang, H., Kleissl, J., Suselj, K., Kurowski, M. J., \& Teixeira, J. (2020). On the parameterization of convective downdrafts for marine stratocumulus clouds. Monthly Weather Review, 148(5), 1931-1950. https://doi.org/10.1175/MWR-D-19-0292.1

Zelinka, M. D., Randall, D. A., Webb, M. J., \& Klein, S. A. (2017). Clearing clouds of uncertainty. Nature Climate Change, 7, 674-678. https://doi.org/10.1038/nclimate3402

Zhou, X., \& Bretherton, C. S. (2019). Simulation of mesoscale cellular convection in marine stratocumulus: 2. Nondrizzling conditions. Journal of Advances in Modeling Earth Systems, 11(1), 3-18. https://doi.org/10.1029/2018MS001448 